\title{
Polymers and the Environment
}

\author{
Telmo Ojeda
}

Additional information is available at the end of the chapter

http://dx.doi.org/10.5772/51057

\section{Introduction}

The traditional polymer materials available today, especially the plastics, are the result of decades of evolution. Their production is extremely efficient in terms of utilization of raw materials and energy, as well as of waste release. The products present a series of excellent properties such as impermeability to water and microorganisms, high mechanical strength, low density (useful for transporting goods), and low cost due to manufacturing scale and process optimization [1]. However, some of their most useful features, the chemical, physical and biological inertness, and durability resulted in their accumulation in the environment if not recycled. Unfortunately, the accumulation of plastics, along with other materials, is becoming a serious problem for all countries in the world. These materials occupy significant volume in landfills and dumps today. Recently, the presence of huge amounts of plastic fragments on the oceans has been observed, considerable part of them coming from the streets, going through the drains with the rain, and then going into the rivers and lakes, and then to the oceans [1]. As a result, there is a very strong and irreversible movement, in all countries of the world, to use materials that do not harm the planet, that is, low environmental impact materials.

In this chapter, alternatives to traditional polymers derived from fossil fuels are commented. Materials derived from plants and microorganisms are presented, as well as biodegradable materials obtained from fossil fuels.

\section{Overview of the fate of polymeric wastes}

Of course, before we use materials that can accumulate in nature, we must think about reducing their consumption, reusing and recycling (either by reuse of raw materials, or by use of the energy of combustion) [3]. However, certain parts that are formed by small amounts of polymer (ie, a few grams) and may still be contaminated by food are difficult to be collected from nature, cleaned, sorted and recycled, both from the economic and also 
from the environmental (energy consumption and soil pollution of the process) point of view. This is the case of plastic bags and packaging, especially plastics used in food, in medical and hygiene. In these cases, the use of biodegradable polymer materials may be an excellent solution to the environment [2].

Precisely for this reason, we are now receiving a huge load of information on plastic materials with less impact to the environment. And much of this information is contradictory, not bringing acceptable scientific references on the assertions made. Even the norms for biodegradation tests have been developed under influence of the manufacturers of biodegradable products as a tool to ward off competitors.

Despite the somewhat confusing situation we are currently experiencing, the products on the market are being tested by consumers and the trend is that the most suitable materials in every situation be known over time. Nevertheless something is right: the best product for a given application in a given market may not be the same for another application and/or another market. An important aspect to consider is to know where the polymer material will be disposed, to evaluate the conditions for biodegradation. Some polymers that biodegrade well in industrial composting conditions (high temperatures, high levels of moisture and oxygen) biodegrade much more slowly in the soil at ambient temperatures, PLA (or polylactic acid) being an example. In landfills, all polymers biodegrade very slowly, due to restrictions of oxygen and moisture in the layers below the surface. Biodegradation under anaerobic conditions (deprived of oxygen) produces $\mathrm{CH}_{4}$ (methane), $\mathrm{CO}_{2}$ (carbon dioxide), water and biomass (living cells). Methane is a much more potent gas than $\mathrm{CO}_{2}$ to the greenhouse effect. Biodegradation under aerobic conditions (oxygen abundance), otherwise, does not produces methane, producing mainly $\mathrm{CO}_{2}$, water and biomass [4].

Biodegradability is a feature that has been highly valued in polymers from the environmental standpoint, but is not the only important one. Sooner or later, all components in a polymer material will be returned to the environment, with the degradation, so it is very important to use pigments, fillers and additives that are not toxic in nature. Furthermore, the environmental impacts should be studied from birth to death of the polymer (or "from cradle to grave"). The use of raw materials from renewable resources (plants) has also been highlighted. However, one point to be considered here is the use of arable land for monocultures in farms that could be producing food and are instead producing raw materials for commodities (like plastics). Likewise, one must consider the possibility of using fertilizers and pesticides in excess, what could impact in eutrophication, acidification, global warming, poisoning of the environment, etc. Another point is to know if the farming practices are conservationists or not, ie, if they seek to preserve the soil or not. For example, the practice of burning crop residues after harvest should be avoided. Another interesting aspect is the one of polymer production. Very complex processes with many steps, which consume much energy and generate much waste tend to be disadvantaged. The need for transportation of raw materials to the factory or of finished products to the consumer market must also be considered. All the characteristics above are usually considered in the life cycle assessment of the product, which, being somewhat complex, can be aided by regulatory standards (e.g. series EN - ISO 14040) [5-7]. 
During the 1960s percipient environmentalists became aware that the increase in volume of synthetic polymers, particularly in the form of one-trip packaging, presented a potential threat to the environment, what became evident in the appearance of plastics packaging litter in the streets, in the countryside and in the seas [8].

PVC (see Figure 1) is a good example. Although the density of PVC is around 1.4, hollow parts may float in the oceans, which have a density of about 1.03. PVC has a high concentration of chlorine atoms in an organic chemical structure that is new in nature (i.e. a xenobiotic), what renders it very recalcitrant [9]. On the other hand, PVC degrades easily under the action of light or heat, and its decomposition is catalyzed by the $\mathrm{HCl}$ released, forming a poly-unsaturated structure which is very degradable. In oceans the $\mathrm{HCl}$ might be removed by the moving water and also neutralized by the cations existing in the alkaline medium ( $\mathrm{pH} \sim 8$ ). To increase stability, 1 to $5 \%$ of additives based on transition metals, such as salts, derivatives and complexes of $\mathrm{Pb}, \mathrm{Zn}, \mathrm{Cd}$ and $\mathrm{Sn}$ are commonly employed [10]. In order to get a more flexible PVC, plasticizers based on phthalate are commonly used, many of them having chronic toxicity to animals, showing body growth problems (ie, teratogenic effects) and reproduction complications in humans. Small fragments of PVC molecules can evaporate. Just as halogenated solvents, these molecules are very inert and can rise to the stratosphere, contributing to the destruction of the ozone layer [9]. In addition to the accumulation in the environment and to the possible toxicity of the additives, it was realized that the incineration of PVC generated many toxic products such as dioxins, due to the high concentration of chlorine atoms present [1].

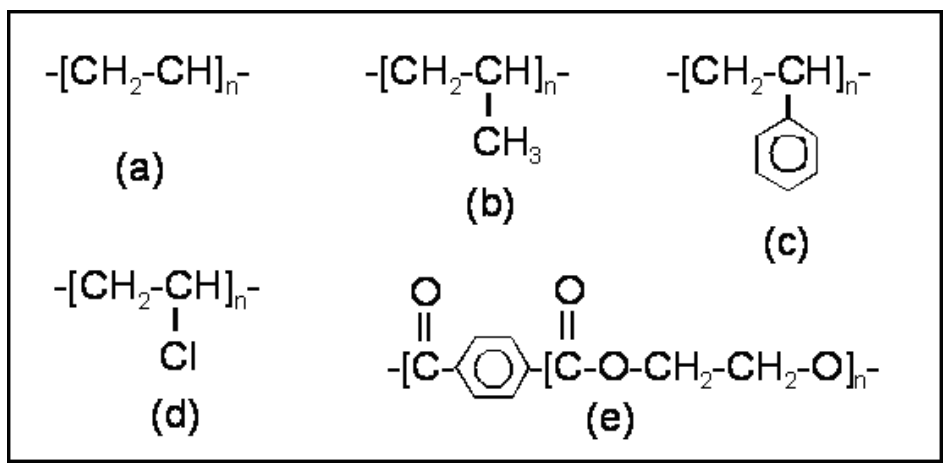

Figure 1. Basic structures of the main thermoplastic polymers in the present: a) polyethylene (PE), b) polypropylene (PP), c) polystyrene (PS), d) polyvinyl chloride (PVC), and e) polyethylene terephthalate (PET).

Polycarbonate (plastic) and epoxy resins (coating and adhesive) are normally produced with bisphenol A as one of the monomers. This substance may also be used as an additive for plastics. It is an endocrine disruptor (it can mimic hormones) [1]. Some studies have shown toxicity, carcinogenic effects and possible neurotoxicity at low doses in animals [1115]. In the case of decomposition of the resin, this toxic monomer might be released into the 
environment. Polycarbonate can be recycled. Its biodegradation is very slow due to the presence of aromatic rings in the main chain.

Polystyrene (PS, Figure 1) has a density of about 1.05, but hollow parts made with this polymer may fluctuate in the oceans. The presence of aromatic rings at a short distance from the main chain increases its resistance to biodegradation (ie., its recalcitrance). In addition, PS has rigid (although not crystalline) molecules, making difficult the enzymatic action. Although most of the additives used with PS are not toxic, the residual amounts of free styrene, "dimers" and "trimers" (obtained after polymerization) must be kept very low, because they are volatile and can migrate out of the part [16]. This polymer can be recycled.

Polyethylene terephtalate (PET, Figure 1) has a density around 1.4, but again bottles and other parts made with this polymer may float in the ocean until they fracture. PET presents aromatic rings in the main chain, which makes it highly recalcitrant, despite having hydrolysable ester groups. Additionally, catalysts residues employed in their synthesis (either by esterification or transesterification) are present in the polymer. Examples of catalysts are manganese, zinc and cobalt salts (transesterification) and compounds of antimony, germanium, titanium and tin (esterification) at typical concentrations of 50-250 ppm [17]. Phosphorus compounds used to deactivate transesterification catalysts can cause eutrophication of ocean waters. PET has been reused and recycled on a large scale in many countries around the world.

Polyamide 11 (PA 11) is a biopolymer derived from vegetable oil. It is commercialized by Arkema and DSM. PA 11 belongs to the technical polymers family and is not biodegradable. Its properties are similar to those of PA 12, although emissions of greenhouse gases and consumption of nonrenewable resources are reduced during its production. It is used in high-performance applications like automotive fuel lines, pneumatic airbrake tubing, flexible oil and gas pipes, sports shoes and electronic device components [18].

The nylon 6 and nylon 66 polyamides are considered polymers with superior thermal and mechanical properties, and are therefore referred to as engineering polymers. Although they are in the group of the non-biodegradable polymers [19], they may be significantly degraded by white-rot lignin degrading fungi. Its surface erosion suggests that nylons are degraded to soluble monomers [20]. They can be degraded by hydrolysis and also by oxidation. In the latter case, the more reactive hydrogen atoms are those attached to the carbon atom adjacent to the nitrogen atom of the amide group [21].

Polyurethanes (PURs), or carbamates are polyethers or polyesters (with molecular weight of about $200-6000 \mathrm{~g} \cdot \mathrm{mol}^{-1}$ ) copolymerized by a polyaddition process, with monomers containing isocyanate groups, resulting the characteristic urethane groups in the main chain, which are generally in very low proportions. In most applications, they are thermosetting or thermo-crosslinkable polymers, ie they form a three-dimensional network by chemical reactions under heating, and they do not soften under further heating [1]. The company Cargill produces polyol for polyurethane cushioning, which is soy-based ( $\mathrm{BiOH}$ polyol), designed especially for flexible foams. 
It is believed that most of PUR biodegradation occurs by the action of esterases, however polyester-polyurethane degrading enzymes have been purified and their characteristics have been reported. These enzymes have a hydrophobic binding domain at the surface of the PUR, and a catalytic domain [22]. But there is no evidence that the urethane linkage has been broken.

Polyolefins are polymers produced by the polymerization of alkenes, such as polyethylenes (PEs, Figure 1), polypropylene (PP, Figure 1), polybutene-1 (PB-1) (plastics), polyisobutylene (PIB), ethylene-propylene-rubber (EPR), ethylene-propylene-diene monomer (EPDM) (elastomers), etc. They are a very large class of carbon-chain thermoplastics and elastomers, the most important being polyethylenes and polypropylene. They are extensively used in many different forms and applications. Flexible packaging, included here wrap films, grocery bags and shopping bags made with extruded films and extruded blown films, as well as rigid packaging made by blow moulding and injection moulding represent a considerable amount of the total material consumed [1]. Polyolefins float in the oceans, because they are normally lighter than salty water. They do not normally contain toxic ingredients, although toxic metals may be introduced as pigments. Usual additives are antiacids (e.g., $\mathrm{Mg}$ or Ca stearates at $\sim 0.1 \%$ ) and antioxidants (e.g., hindered phenols and phosphites at $\sim 0.05-0.2 \%$ ). Catalytic residues, such as $\mathrm{Ti}$ and $\mathrm{Cr}$ compounds, are present at very low levels (ppm). The oxidative degradation of polyolefins in the oceans is favored by the continuous movement of the waves, by the presence of oxygen at the surface, and by the sun exposure. On the other hand, the temperature of plastic materials at sea does not reach that on the ground, due to the effect of heat removal by water. Eventual fouling can limit the exposure of the material to UV radiation. Oxidized residues of polyolefins may sink into the sea due to the change in density that occurs during oxidation. This behavior slows down subsequent degradation/biodegradation, as in deep water there is no UV radiation, the amount of oxygen available is very limited, the temperature is lower $\left(\sim 4^{\circ} \mathrm{C}\right.$, reaching even $1^{\circ} \mathrm{C}$ ) and there is no agitation by waves. In fact, even the food present in sunk ships degrades and biodegrades very slowly on the sea bottom.

Although the above polymers have a number of environmental impacts from the time of their disposal, their production from oil, natural gas or coal has been optimized through decades of manufacturing. In the case of petroleum, the petrochemical industry uses naphtha, that is a petroleum fraction of approximately $3 \%$ of the total. Should naphtha not be used for the petrochemical industry, it would then be burned, what would not improve anything its environmental impact. Moreover, the use of oil to be burned in a combustion engine or in a boiler for heat is becoming an unacceptable luxury to the present day, with the prices of fossil fuels becoming progressively higher. The use of fossil fuels as raw materials, as major carbon sources, appears to be more compatible with the world reality today. The development of renewable forms of energy such as solar thermal and photovoltaic, wind, hydroelectric, wave and tidal, geothermal, biogas and others should allow the replacement of the energy obtained from fossil fuels in a few decades.

Biopolymers: are polymers produced by living organisms. They all have been around for millions of years on our planet, and for this reason microorganisms have had enough time 
to develop enzymes capable of degrading their structure, so they are biodegradable. In general their end of life environmental impact is low. However, there are at least two cases where this is not true:

1. When the biopolymer is placed in an unsuitable environment for its biodegradation. For example, a landfill does not provide adequate conditions for biodegradation, since oxygen and water are lacking. Under anaerobic conditions (ie in the absence of oxygen), the biopolymer, as well as organic wates in general, will degrade producing biomass, methane $\left(\mathrm{CH}_{4}\right)$, carbon dioxide $\left(\mathrm{CO}_{2}\right)$ and water, as well as other eventual small molecules $\left(\mathrm{NH}_{3}, \mathrm{~N}_{2}, \mathrm{~N}_{2} \mathrm{O}, \mathrm{H}_{2} \mathrm{~S}\right.$, mercaptans, etc.), depending on its chemical structure. The generated methane is a much more powerful gas than carbon dioxide to global warming, and is not readily reabsorbed by plants, as with $\mathrm{CO}_{2}$.

2. Once the biopolymer is mixed with other polymers in a recycle stream, it will act as a contaminant, as biopolymers are normally not recyclable, degrading at the recycling processing conditions.

If we look now to the environmental impacts that occur since the extraction/transportation/processing of raw materials to the final production of the biopolymers, we observe that the final balance can be even worse than that of conventional polymers obtained from petroleum. A comparative study of all environmental impacts of a particular product (eg a polymer) can be obtained by a life cycle assessment. The life cycle assessment (LCA) of a product, process or activity is a technique to assess environmental impacts, or the environmental burdens associated with all the stages of its life, from cradleto-grave, ie: extraction, transportation and processing or raw materials; manufacturing; transportation and distribution; use, reuse and maintenance; recycling; final disposal; material and energy consumption; water consumption and emissions generation; etc. The assumptions and methodologies should be given, and should be clear, consistent and documented, otherwise it may be impossible to compare different LCA studies. Some of the most often evaluated environmental impacts are: toxicity to humans or to other living organsms; fresh water aquatic ecotoxicity; marine aquatic ecotoxicity; terrestrial ecotoxicity; eutrophication, acidification (of rains and soils); global warming potential; ozone depletion; abiotic depletion of mineral resources; depletion of fossil fuels (petroleum, natural gas and coal); visual pollution (litter); photochemical oxidation (smog formation); renewable and non-renewable energy use [5-7]. A difficulty in comparing different types of environmental impacts is the use of a different unit to each type assessed. For example, $\mathrm{kg} \mathrm{CO}_{2}$ equivalent is the required $\mathrm{CO}_{2}$ mass to produce the same effect (global warming) that the object of study. Then how to compare global warming with, for example, abiotic depletion, which has the unit $\mathrm{kg}$ Sb equivalent (resource depletion compared with that of antimony)? The weight of each impact needs to be arbitrated in order to calculate the total impact. An impact that is very significant for some authors may be considered less important for others. Therefore, all assumptions made need to be transparent in the study.

The findings of some LCAs studies of plastic bags are presented below. In a study by Edwards and Fry [5], the authors have concluded that the environmental impacts of all types of carrier bags are dominated by resource use and production stages, whereas 
transport, secondary packaging and end-of-line management have minimal influence. According to them the key to reducing the impact is to reuse the bags as many times as possible, at least as bin liners. Reuse produces greater benefits than recycle. Recycling or composting generally produce small reductions in global warming potencial and abiotic resource depletion. They found that starch-polyester bags have significant global warming potential and abiotic depletion. The impacts of the oxo-biodegradable high density polyethylene (HDPE) bags are very similar to the conventional HDPE bags, because of the similarity in material content and use. The production of the pro-oxidant additive has minimal impact on most life cycle categories. End-of-life impacts through incineration and landfill are practically identical. The essential difference, although not concluded by the authors, seems to be that oxo-biodegradable HDPE bags do not remain on ground or water as litter, and that they represent a source of carbon, just like humus.

James and Grant [6] have found in their study that polymer based reusable bags have lower environmental impact than all single-use bags evaluated. Degradable bags have similar greenhouse and eutrophication impacts to conventional HDPE bags, because they normally go into landfills. Decisions about degradable polymers should be based on: where and how they will degrade, minimal LCA (not just end-of-life), and commercial benefits.

Tabone et al. [7] assessed plastic bags according to two sets of parameters: green design principles and life cycle assessment - environmental impacts. The first one was related to several general principles, like prevent waste, utilize less material mass, maximize energy efficiency, use non-hazardous inputs, use renewable feedstocks, use local sources, design for recycle, minimize material diversity, degrade after use, maximize cost-efficiency, minimize the potential for accidents, etc. The second one referred to LCA, which was discussed above. They have found that, while biopolymers rank highly in terms of green design, they exhibit relatively large environmental impacs from production. The impacts from biopolymers result from the use of fertilizers, pesticides and arable land required for agriculture production, as well as from the fermentation and other chemical processing steps. Interestingly, HDPE and PLA (polylactic acid) are relatively close in terms of the sum of all environmental impacts. Polyhydroxy alcanoates (PHAs) produced from stover have obtained an excellent environmental position.

As a conclusion of some LCAs, it comes out that there is not a single ideal material or solution adequate for all possible situations on Earth, which always presents the lowest environmental impact. A practical present solution for the plastic bags could be the conventional polyolefin materials formulated with pro-oxidant additives, used as many times as possible. Another interesting solution is the use of agricultural and other organic residues as raw materials for the manufacture of biodegradable polymers. Recycling and composting units should be encouraged in all countries of the world. Renewable energies should substitute the fossil fuels, which should be destinated as a carbon source for the chemical industry.

\section{Polymer degradation}

There are three main possibilities of degradation of the polymers: enzymatic, hydrolytic and oxidative. The enzymatic degradation, or biodegradation, is the breaking of polymer chains 
by the action of enzymes, which are natural catalysts of chemical reactions produced by living organisms. For example, cellulose and starch are degraded by specific groups of enzymes known as cellulases and amylases, respectively. Polyesters can be degraded by esterases enzymes $[23,24]$.

The degradation by hydrolysis consists in breaking certain chemical bonds such as ester, ether and amide, by attack of water molecules. This process can be catalyzed by both acids and bases (saponification). In the case of the ester linkage, a carboxylic acid (or a salt thereof) and an alcohol are produced. The ether linkage is much more resistant to hydrolysis than the ester one, generating two alcohols. Hydrolysis of the amide group results in an amine and a carboxylic acid.

The oxidative degradation consists of several different chemical reactions that take place when free radicals (macrorradicais) are formed in the polymer chains in the presence of oxygen. Free radicals may be formed by the action of ultraviolet radiation from the sun, heat, and mechanical deformation (shear and elongation of the chain during processing, or deformation of the solid material by mechanical action, for example, by the action of water and air) $[23,24]$.

In most traditional polymer materials, e.g. polyethylenes and polypropylene, the prevailing action of the oxidative degradation is the breakdown of molecular chains into smaller segments containing oxygen incorporated in the form of hydroxyl, ketone, ester, aldehyde, ether, carboxyl, etc. $[25,26]$. Unsaturations are also formed in the process. Oxidation of polymer materials is a process that occurs naturally, but may take decades or even centuries to be completed. The presence of certain transition metals (such as $\mathrm{V}, \mathrm{Mn}, \mathrm{Fe}, \mathrm{Co}, \mathrm{Ni}, \mathrm{Cu}$ ) accelerates the degradation by a factor of about $10^{2}$ and thus permits the complete degradation within a few years under favorable conditions [27, 28].

\subsection{Conventional polymers}

The chemical formulas of some polymer materials produced in greater amounts worldwide are shown in Figure 1. The typical average molecular weights (weight average) range from 30,000 to $1,000,000$ gmol $^{-1}$ or higher, depending on the polymer applications, therefore " $\mathrm{n} "$ can be varied between several tens and hundreds of thousands. It is observed from the figure that all polymers have chemical structures that impart low polarity, that is, low affinity to water. The high molecular weight and the hydrophobicity are two decisive characteristics for the observed recalcitrance (i. e., bio-resistance, persistence in the environment). Additionally, the chlorine atoms and the aromatic rings are structures that further hinder biodegradation.

Polyethylene (Figure 1), according to the process of production, may present short and long branches and at variable levels. Branches generally difficult the ordered packaging of the chains in crystals, thus reducing the degree of crystallinity, what increases the availability of the polymer to the attack by various chemical species, such as free radicals and oxidase enzymes. Moreover, the branching points are constituted by tertiary carbon atoms, which are more easily attacked by free radicals than primary and secondary carbon atoms. On the 
other hand, although branched molecules are more susceptible to oxidative abiotic degradation, their subsequent biotic degradation by means of $\beta$-oxidation of fatty acids (a carboxyl group being assumed at the chain end) may be delayed, because the enzymes involved require straight hydrocarbon chains.

In polypropylene (Figure 1) a third of the carbon atoms are tertiary, so the polymer is highly susceptible to degradation by free radicals (even in the absence of oxygen). Its high degradability requires the use of antioxidant additives in high concentrations. However, the presence of a methyl branch per repeat unit impairs the biotic degradation via $\beta$-oxidation of fatty acids.

In polystyrene (Figure 1), the most vulnerable site to oxidation is the main chain carbon which binds to the phenyl group, that may lose a hydrogen atom, generating a free radical. Furthermore, the phenyl group is UV absorber, and can generate free radicals. The phenyl side groups are distributed unevenly in the chain, preventing PS to crystallize [29], contrary to what occurs with PP, where the distribution of methyl groups is regular (isotactic). Though not crystalline, PS chains are very rigid (the glass transition temperature, or $\mathrm{Tg}$, of PS is well above room temperature, (see Table 2), what hinders the action of degrading enzymes.

The PVC resin (Figure 1), as the PS, has the side groups (chlorine atoms) distributed unevenly, being predominantly non-crystalline. The chains are rigid at room temperature, since the Tg is relatively high, but the addition of plasticizers imparts mobility to the chains (lowers Tg). Many of the used phthalates plasticizers present chronic toxicity to animals, showing teratogenic effects, i. e., causing malformations of an embryo or a fetus $[9,10]$. PVC degrades easily under the action of light or heat, and its decomposition is self-catalised by the released $\mathrm{HCl}$. To enhance the stability, toxic additives based on transition metals are normally used, as already mentioned [10].

In PET (Figure 1), the points that are most susceptible to oxidative attack are the atoms at the alpha position relative to the ester group. Furthermore, hydrolysis of the ester group is also possible. The hydrolysis lowers the $\mathrm{pH}$, what accelerates the degradation. Hydrolysis is also accelerated by temperature, UV radiation and chemicals such as acids, bases and certain transition metals. On the other hand, the ester linkage is highly stabilized by the aromatic rings in the main chain, that also confer rigidity to the chains $[17,30]$.

\section{Biodegradable polymers}

Biodegradable polymers are those polymers that, under certain conditions (e. g., in the soil, at room temperature and under aerobic conditions) can be degraded directly by the action of enzymes or after passing through an initial period of hydrolytic or oxidative degradation. The main degrading organisms are fungi, bacteria and archaea, although algae, nematodes, and even insects can also be involved. In aerobic environments, the degradation produces $\mathrm{CO}_{2}, \mathrm{H}_{2} \mathrm{O}$ (among other gases) and biomass, i.e., living cells. In anaerobic conditions, $\mathrm{CH}_{4}$ (methane) is additionaly produced (among other gases). The biodegradable polymer serves as a source of carbon and energy to the microorganisms. But other nutrients are also needed for maintaining microbial activity, such as $\mathrm{O}, \mathrm{H}, \mathrm{N}, \mathrm{P}, \mathrm{S}, \mathrm{Cl}, \mathrm{Na}, \mathrm{K}, \mathrm{Mg}, \mathrm{Ca}, \mathrm{Mn}, \mathrm{Fe}, \mathrm{Co}, \mathrm{Ni}$, 


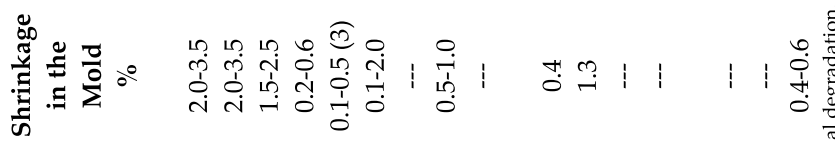

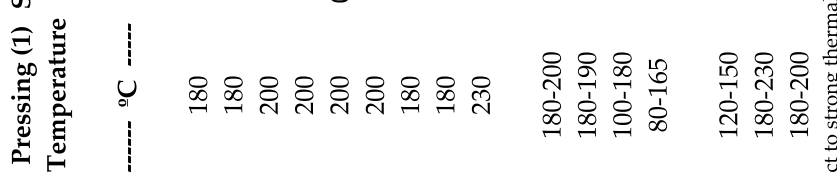

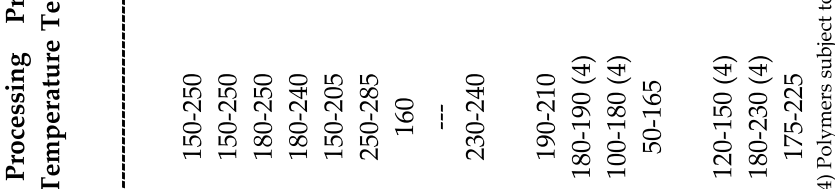

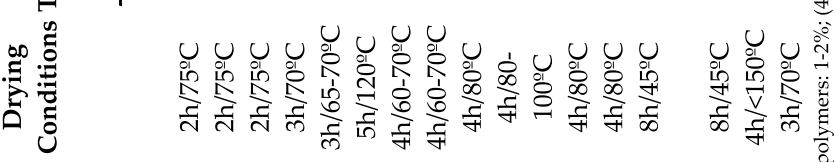

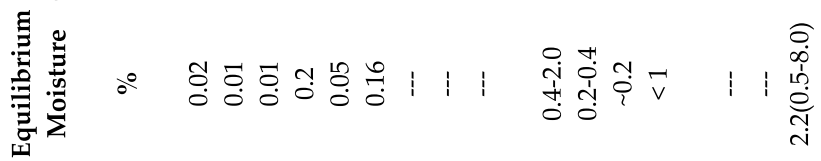

क्षे

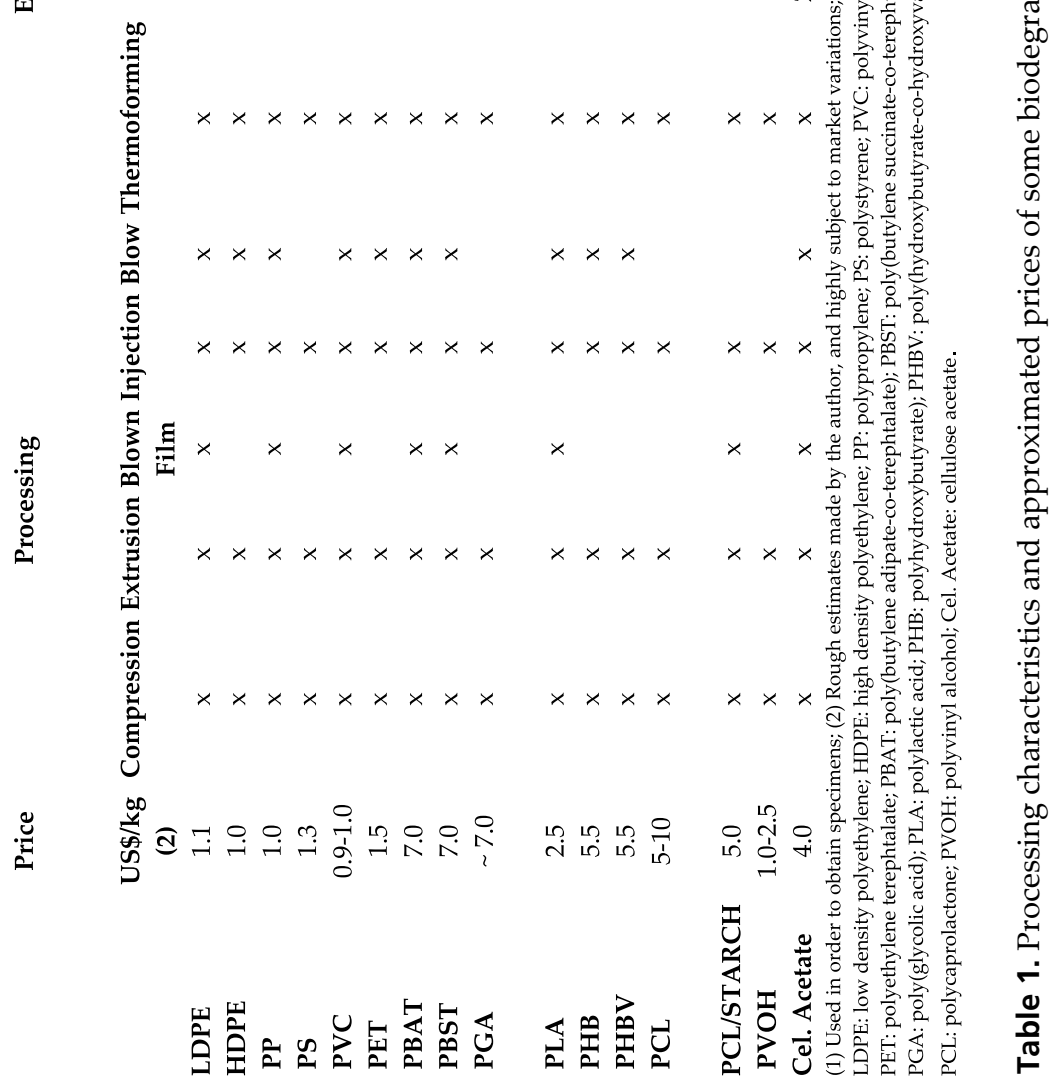




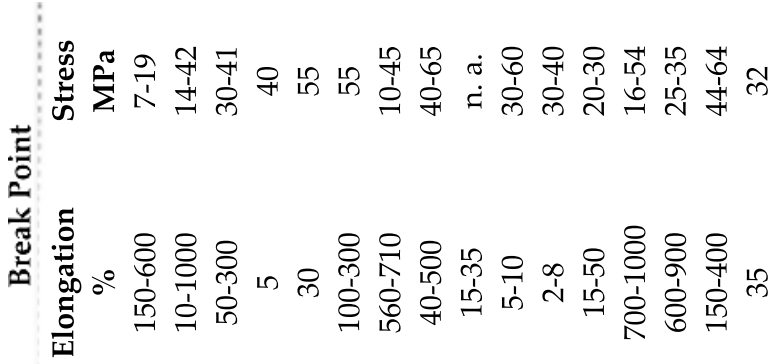

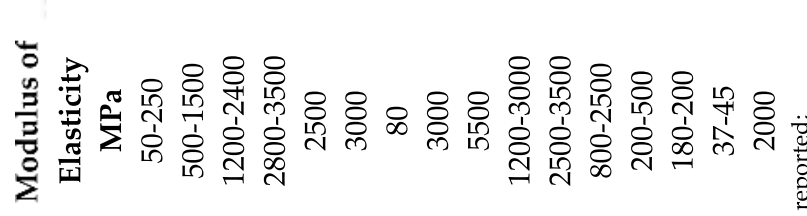

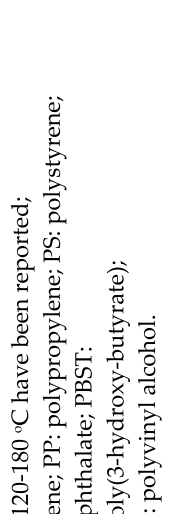

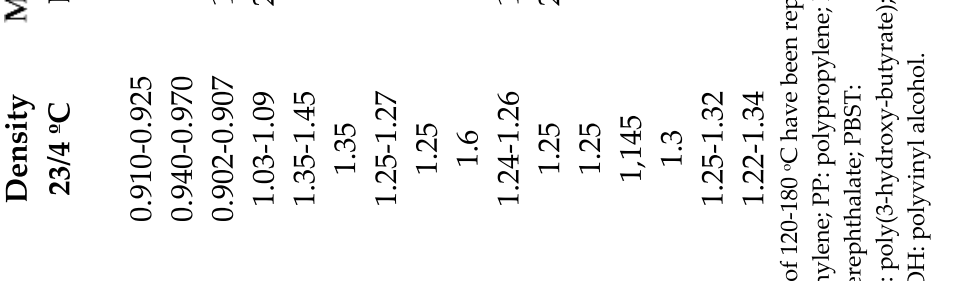

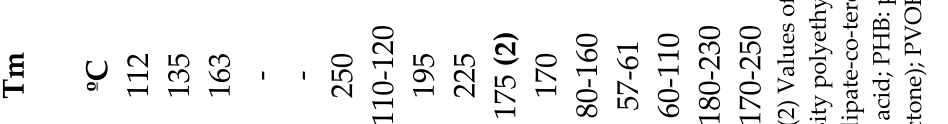


$\mathrm{Cu}, \mathrm{Zn}$ and Mo. The presence of water is essential to all known living organisms. Regarding the oxygen requirement, there are the following classes of organisms: obligate aerobes (need $\mathrm{O}_{2}$ ), obligate anaerobes (are killed by $\mathrm{O}_{2}$ ), microaerophiles (live only at low $\mathrm{O}_{2}$ concentrations), facultative anaerobes (live with or without $\mathrm{O}_{2}$ ) and aerotolerant anaerobes (not affected by $\mathrm{O}_{2}$ concentration).

There are currently biodegradable polymers with characteristics and properties very similar to those from conventional polymers derived from petroleum (Tables 1 and 2).

Many factors may affect biodegradation. With respect to the material itself, the following factors have influence: chemical structure, molecular weight, degrees of branching and crosslinking (if present), glass transition temperature, crystallinity and solubility, and concentration of additives and pigments. With regard to the environment, the following factors have influence: presence of water, oxygen and other nutrients (in particular, the ratio $\mathrm{C}: \mathrm{N}: \mathrm{P}$ ), temperature, $\mathrm{pH}$, osmotic pressure (concentration of ions and solutes in the environment), surface area of the part, and the available microbial population [31].

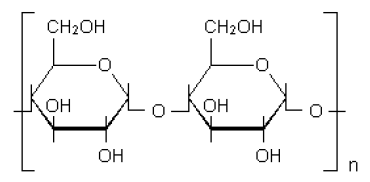

amylose

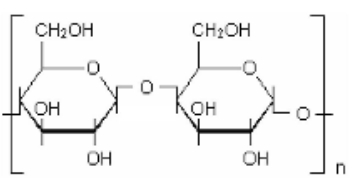

cellulose<smiles>CCC(O)CC</smiles>

$\mathrm{PVOH}$<smiles>CC(C)OC(=O)C(C)C</smiles>

PLA<smiles>CCOC(=O)CC(C)C</smiles>

PHB<smiles>CCOC(=O)CC(CC)OC(=O)CC(C)C</smiles>

PHBV<smiles>CCC(=O)OCCCCCC(C)(C)C</smiles>

PCL<smiles>CC(C)(C)OCCCCOC(=O)c1ccc(C(=O)C(C)(C)OCCCCOC(=O)CCC(=O)C(C)(C)C)cc1</smiles>

PBST<smiles>CC(C)(C)OCCCCOC(=O)c1ccc(C(=O)C(C)(C)OCCCCOC(=O)CCCCC(=O)C(C)(C)C)cc1</smiles>

PBAT

Figure 2. Chemical structures of some biodegradable polymer materials: PVOH: polyvinyl alcohol, PLA: polylactic acid, PHB: poly(hydroxybutyrate), PHBV: poly(hydroxybutyrate-co-hydroxyvalerate), PCL: polycaprolactone, PBST: poly(butylene succinate-co-terephtalate), PBAT: poly(butylene adipateco-terephtalate).

The vision that a single species will be responsible for the complete degradation of a substrate (polymer) is very common but unrealistic, because xenobiotics are normally 
degraded by consortia of different species of fungi, bacteria and archaea, among other organisms. Symbiosis, commensalism and co-metabolism are common events. The polymers are degraded by steps by the consortium, each step through one or more enzymes produced by one or more organisms. The final products of degradation are mostly $\mathrm{CO}_{2}, \mathrm{H}_{2} \mathrm{O}$ and biomass under aerobic conditions, and additionally, $\mathrm{CH}_{4}$, under anaerobic conditions.

The first group of polymer materials is comprised of inherently biodegradable materials, i. e. those whose molecules can be biodegraded immediately after coming into contact with microorganisms from soil, composting plants, rivers, etc. Examples of this group are modified starch and cellulose (Figura 2), proteins and their derivatives (i. e., products made of these materials after chemical modifications and/or mixing with other materials). The polymer materials produced by plants or other living organisms are called biopolymers or bioplastics, if they are plastic.

\subsection{Group of polysaccharides}

\subsubsection{Starch}

Starch is a polymer of the group of polysaccharides, to which also belong cellulose, hemicellulose and chitin, among others. Its chemical composition depends on the plant, but generally comprises a mixture of $20-30 \%$ by weight amylose (Figure 2) and $70-80 \%$ by weight of amylopectin. Amylose and amylopectin have molecules formed by glycosidic units bond by $\alpha-1,4$ ether linkages. Amylose consists of about 200 to 12,000 glycosidic units, forming a straight chain without branching, with secondary (space) helical structure. Amylopectin consists of about 0.6-2.5 millions of glycosidic units, and is strongly branched. The branches are formed by $\alpha-1.6$ ether linkages, with average length of 20-30 glycosidic units, occurring every $24-30$ units of the straight chain $[32,33]$. The chain regions next to the branches are included in the amorphous phase of the material. The chains of the crystalline phase normally have the helix conformation. As a consequence of its molecular structure, starch has lower degree of crystallinity than cellulose, what facilitates its biodegradation. Just as cellulose, starch is not a thermoplastic material, due to the intensity of the interaction between the molecules by $\mathrm{H}$ bonds. Thus heating and shear forces result in degradation before melting. The mechanical properties are poor, both stiffness and toughness, and related properties.

Starch is usually obtained from corn, potato and cassava, although it may be obtained from other sources as well. The fact that it is obtained from foods, that require fertile soil for cultivation, has been much questioned, considering that more than $10 \%$ of the world population is still undernourished today. From the viewpoint of the life-cycle analysis, products from plant or food wastes are highly favored.

In order to prepare thermoplastic starch, the crystal structure of starch has to be destroyed, either by mechanical working, pressure or heat, or by addition of plasticizers, such as water and glycerin. The gelation of starch is the disruption of the semicrystalline structure of its granules during heating in the presence of water over $90 \%$ [32]. The gelation process occurs 
in two steps. The first, at $60-70{ }^{\circ} \mathrm{C}$, is the swelling of the granules, with little leaching, but with loss of chain organization in crystals. The second above $90{ }^{\circ} \mathrm{C}$, causes the complete disappearance of the granular integrity due to events of swelling and dissolution, making the swollen granules vulnerable to shear.

The destructuring of starch is defined as the melting and the disorganization of the molecular structure of the starch granules and subsequent molecular dispersion in water. The thermoplastic starch product has a starch content above $70 \%$ (e. g., $85 \%$ ), being based on gelled and destructured starch, and on the use of plasticizers, allowing the use of conventional equipment for thermoplastic processing. A problem that can also be an advantage is the high hygroscopicity and solubility in water [34].

To improve processability, mechanical properties and moisture resistance while maintaining biodegradability, starch may be mixed with aliphatic or aliphatic-aromatic polyesters, such as polycaprolactone (PCL), polylactic acid (PLA) and poly(butylene adipate-coterephthalate) (PBAT), suffering complexing with these polymers [33, 35].

The complex formed by amylose with the complexing agent is usually crystalline, characterized by an amylose single helix around the complexing polymer [32]. Amylopectin does not interact with the complexing polymer, remaining in the amorphous phase. Starch can also be blended with polyvinyl alcohol (PVOH), for the production of foamed products, such as trays for food. Starch esters reinforced with natural fibers exhibit properties similar to those of polystyrene (PS).

Among the world's leading suppliers are: Novamont (Mater-Bi products) and its licensees (about 80,000 t per year), Rodenburg (Solanyl products, 40,000 t per year), Corn Products, Japan Corn Starch, Chisson, Biotec, Supol, Starch Technology, VTT Chemical, Groen Granulaat and Plantic. The price of the blends of starch with polyesters is about US\$ $5 \mathrm{~kg}^{-1}$, while the price of the modified starch is about US\$ $1.0-1.5 \mathrm{~kg}^{-1}$.

Starch is biodegraded by amylases in a huge variety of different environments. The biodegradation of starch results from the enzymatic attack of the glycosidic linkages, reducing the chain size and producing mono-, di- and oligosaccharides, easily metabolized by biochemical pathways.

Some manufacturers still mix low levels of starch with polyethylene. The rapid biodegradation of the former increases the available surface of the latter to degradation. Possibly, some of the starch degrading microorganisms may also help with the slow biodegradation of polyethylene [36]. Erlandsson et al [37] have tested a system of starch with LDPE, SBS copolymer, and manganese stearate, after thermo-oxidation at 65 and $95{ }^{\circ} \mathrm{C}$ and UV radiation. The starch has stabilized PE regarding thermo-oxidation, but has promoted its photo-oxidation. Among the applications for starch, are films for packaging, shopping bags, garbage bags, mulch films, disposable diapers, foams, foamed trays for food, injection moulded products, blown bottles and flasks, filaments, etc.. The foaming process involves melting (or softening) the polymer and blending it with a foaming agent, typically pentane or carbon dioxide. It is used mainly for polystyrene (PS). 


\subsubsection{Cellulose}

It is the main component of plants, with natural production per year estimated at 7.5 billion tons, and annual human consumption estimated at 200-250 million tonnes. In wood, the cellulose fibrils are joined together by lignin, which is a resin binder.

Cellulose is a polymer made up of about 7,000-15,000 D-glycosidic units (D-glucopyranose residues, Figure 2), joined by $\beta-1.4$ ether linkages, that form the cellobiose units (two consecutive glycosidic units), which are repeated along the chain [38]. Each glycosidic unit has three hydroxyl groups, that promote strong interactions by hydrogen bonds. The spatial structure allows molecules crystallize in a horizontal plane, forming fibers. As a consequence, cellulose is sparingly soluble and not processable by thermal and mechanical action, i. e. it is not thermoplastic. Cellulose is a rigid material, whose fibers may be used to reinforce other materials. It presents a small elongation capacity. In order to become thermoplastic, it is necessary that about two of the three hydroxyl groups of the glycosidic units be reacted.

Cellulose is biodegraded by the extracellular cellulase enzyme complex, that is induced in most microorganisms [39]. Only a subgroup of cellulase, known as exogluconase, or $\beta-1,4-$ gluconase, can attack the terminal glycosidic bond, and is effective in degrading the small crystals (crystallites) in which neither water nor enzymes can penetrate. A manufacturer of cellulose based films is Innovia (NatureFlex products).

Cellulose acetate is a thermoplastic derivative obtained by partial esterification of the hydroxyl groups with acetic acid or anhydride. With an average degree of substitution of up to 2.5 of the 3 available glycosidic hydroxyl groups per unit, the polymer is still biodegradable [40].

The main applications of cellulose are: timber, furniture and fuel; textiles such as cotton; paper, membranes, and explosives. Important cellulose derivatives are cellulose acetate and cellulose acetate butyrate (thermoplastic esters); ethyl, hydroxyethyl and hydroxypropyl cellulose.

\subsubsection{Other polysaccharides}

Chitin and chitosan: The amount of naturally synthesized chitin is estimated at about 1 billion tons per year, produced by fungi, arthropods, molluscs and some plants. Chitosan is the wholly or partly deacetylated chitin. Because it is biocompatible and biodegradable, it has several biomedical applications: cosmetics, personal care, diet food, treatment for thermal burns, sutures, artificial skin, control of drug delivery, etc.. Its price is between US\$ 15 and US\$ 50 per $\mathrm{kg}$. Chitosan is biodegraded by enzymatic hydrolysis. The higher the degree of acetylation, the lower the crystallinity and the higher the rate of biodegradation obtained [38, 41].

Pectin: is a polysaccharide obtained from citrus peel and remains of apples or other fruits used to obtain juice. It is a bonding material of plant cells. It is used as thickener, gelforming agent, emulsion stabilizer, dietary fiber that is not digested by humans, etc.. 
Xanthan: is a polysaccharide obtained from fermentation of glucose or sucrose by the bacteria Xanthomonas. It is used as food emulsifier additive, rheological modifier (thickener) of oils and cosmetics (with the bentonite), as a stabilizer of aqueous gels, etc.

Pullulan: is a polysaccharide obtained from the fermentation of starch by the yeast Aurobasidium pullulans. It is edible and tasteless. It is used as edible films for food packaging with high oxygen permeability, oral care products, adhesives, thickeners, stabilizers, etc..

Alginates: are a family of copolymers of polysaccharides consisting of $\alpha$-L-guluronic acid blocks $(\mathrm{G})$ and $\beta$-D-mannuronic acid (M) [42]. They may bind to certain ions (e. g. $\mathrm{Ca}^{+2}$ ) through guluronate residues, forming three-dimensional hydrogels. Alginates rich in $G$ blocks bind to a larger number of ions, producing more rigid and resistant gels, whereas alginates rich in $\mathrm{M}$ blocks are more flexible and enable higher diffusion rates of solutes through the gel. Alginates may be produced from natural sources (brown algae), by extraction and purification by sterile filtration. But they may also be produced by fermentation of various microorganisms. Chemically modified alginates are also synthesized: by esterification with propylene oxide (for beers and salad dressings), alkylation with alcohols (drug delivery systems), alkylation or allylation of binder groups (in order to obtain photo-crosslinkable gels). There are several methods to fabricate globules, microcapsules, fibers, films and membranes. Alginates are susceptible to degradation: by cleavage of glycosidic linkages through hydrolysis in acidic or basic environments, by free radical oxidation, and by enzymatic degradation.

\subsubsection{Hemicellulose}

Hemicellulose is a polysaccharide consisting of around 200 monomer units of different sugars, such as xylose (highest contents), mannose, galactose, rhamnose and arabinose, statistically distributed in the chain, which is branched. As a consequence, the material is amorphous, and has low mechanical and hydrolysis resistance. It is easily hydrolyzed by many hemicellulases enzymes from bacteria and fungi. Hemicelluloses are embedded in the cell walls of plants, bond with pectin (another carbohydrate) to cellulose to form a network of cross-linked fibres.

\subsection{Lignin}

Lignin is a complex and heterogeneous cross-linked polymer, containing aromatic rings, C$\mathrm{C}$ bonds, phenolic hydroxyls, and ether groups, with molar mass higher than $10^{4} \mathrm{~g} \mathrm{~mol}^{-1}$. It is formed in chemical association with cellulose, giving lignocellulose, in the cell walls of plants. Thus lignin is not a polysaccharide, but a complex substance consisting of aromatic structures with alkoxy and hydrocarbon substituents that link the basic aromatic unit into a macromolecular structure through carbon-carbon and carbon-oxygen bonds. It is not heterogeneous both in chemical composition and molar mass.

Lignocellulose is strong and tough, and provides physical, chemical and biological protection to the plant. Lignin is resistant to peroxidation (see oxo-biodegradable polymers), as a result of the presence of many antioxidant-active phenolic groups, which act as 
protective agents against abiotic peroxidation and biological attack by peroxidase enzymes [43-45]. Lignin is obtained mainly from wood: $25-30 \%$ of wood is lignin, filling the spaces among cellulose, hemicellulose and pectin in the cell wall of plants. It is also present in some algae. After the cellulose, it is the second most abundant organic polymer on earth, with about 50 million tons being industrially produced annually. It is the main humus-forming component, which provides nutrients and electric charges to the soils. Humus is slowly biodegradable by oxidase and peroxidase enzymes, produced especially by fungi. Although basidiomycetous white-rot fungi and related litter-decomposing fungi are the most efficient degraders of lignin, mixed cultures of fungi, actinomycetes, and bacteria in soil and compost can also mineralize lignin [46].

The main industrial use of lignin is still the power generation, as biofuel. A biodegradable material based on lignin, obtained as a byproduct from the manufacture of paper, mixed with vegetable fibers, is manufactured by Tecnaro under the trade name of Arboform [47]. This is a hygroscopic thermoplastic material, that can be processed at $140{ }^{\circ} \mathrm{C}$. Its mechanical properties show high rigidity and low deformability.

\subsection{Proteins}

Proteins are polymers formed by $\alpha$-amino acids, in which the individual amino acid units, called residues, are linked together by amide (or peptide) bonds. The amide linkages are readily degraded by enzymes, particularly proteases. Soy proteins have been used for edible films and even automotive parts, but proteins have not been consolidated as a thermoplastic of worldwide use [48]. Polyamino acids with free carboxylic groups, such as polyaspartic acid and polyglutamic acid, are excellent candidates for use as water soluble biodegradable polymers [40]. In addition to thermoplastics, other possible applications of proteins are in coatings, adhesives, surfactants and gelatin capsules for pharmaceutical uses.

\subsection{Natural rubber}

Natural rubber is poly (1,4-cis-isoprene), naturally synthesized by the rubber tree, Hevea brasiliensis, present in its milky sap or latex. It is also synthesized industrially by polyaddition of isoprene. The long and flexible molecules $\left(\mathrm{Tg}=-73{ }^{\circ} \mathrm{C}\right)$ give elastomeric characteristics to the material, that is usually crosslinked with a curing agent such as elemental sulfur. It partially crystallizes when stretched. Due to the long sequences of double bonds (one per monomeric unit), this rubber has a high reactivity with oxygen, undergoing the peroxidation reactions, yellowing very quickly, and being biodegraded at a relatively high rate [1]. The hydrogen atoms attached to carbon atoms at the alpha position relative to the unsaturations are more reactive, or more labile [21]. Among the main applications are tires and tubes.

\subsection{Polyvinyl alcohol (PVOH)}

Polyvinyl alcohol is a biodegradable polymer obtained by partial or complete hydrolysis of polyvinyl acetate (PVA, of petrochemical origin) to remove acetate groups (Figure 2). The 
vinyl alcohol monomer almost exclusively exists as the tautomeric form acetaldehyde, which does not polymerize [49].

PVOH is the only water soluble biodegradable polymer, whose main chain consists only of carbon atoms. Solubility and biodegradability are imparted by the hydroxyl groups, that are capable of establishing hydrogen bonds with water. The partial hydrolysis leaves acetate residues, that allow $\mathrm{PVOH}$ solubility in cold water, and decrease the biodegradability. At a hydrolysis level close to $100 \%$, the polymer is soluble only in hot water and is completely biodegradable [49]. Even being an atactic polymer, with non-organized space distribution of the hydroxyl groups in the main chain, $\mathrm{PVOH}$ shows crystallinity, because the hydroxyl groups are small enough to accommodate within the crystal, not hindering it [49].

$\mathrm{PVOH}$ can not be processed by conventional extrusion, because it decomposes (from about $150{ }^{\circ} \mathrm{C}$ up) before reaching its melting temperature of $230{ }^{\circ} \mathrm{C}$, with release of water and formation of terminal unsaturation. Partially hydrolyzed products, with melting temperatures of $180-190^{\circ} \mathrm{C}$, containing internal plasticizer (such as water, glycerol, ethylene glycol and its dimer and trimer, etc.) decompose only slightly during extrusion [50].

Among the leading manufacturers are Hydrolene (Idroplast), Celanese (Celvol), DuPont (Elvanol), Air Products, Kuraray, Hisun, Ranjan and Wacker, as well as some major Chinese producers, working for several years. Annual production exceeds 1 million tons.

Some major applications are: thickener in paint industry; paper coating, hair sprays; shampoos; adhesives; biodegradable products for the feminine hygiene; diapers bottoms; water soluble packaging films (detergents, disinfectants, scouring powder, pesticides, fertilizer, laundry, etc.); fibers for concrete reinforcement; lubricant for eye drops and contact lenses; and material for chemical resistant gloves.

It is believed that the $\mathrm{PVOH}$ degrading microorganisms are not spread throughout the environment, and that they are predominantly bacteria and fungi (yeasts and moulds) [50].

Before the start of biodegradation, a period of acclimatization may be required. Acclimatization (natural conditions) and acclimation (laboratory conditions) are the adjustment process of an organism or a colony to an environmental change, normally occurring in short periods of time (days or weeks).

The biodegradation mechanism consists of a random cleavage of 1,3-diketones, that are formed by the enzymatic oxidation of the secondary hydroxyls [51]. The main three types of PVOH-degrading enzymes are polyvinyl alcohol oxidase (secondary alcohol oxidase), polyvinyl alcohol dehydrogenase and $\beta$-diketone hydrolase [52].

\subsection{Poly(ethylene-co-vinyl alcohol), or EVOH}

$\mathrm{EVOH}$ is a copolymer of ethylene and vinyl alcohol, obtained from ethylene and vinyl acetate, followed by hydrolysis. It is used as an oxygen barrier film in multilayer films for packaging. Its high cost limits its applications as a biodegradable material. 
The second group of biodegradable polymers is formed by hydro-biodegradable materials, i. e. those that need to undergo the chemical process of hydrolysis (breakdown of molecules by reaction with water) before they become biodegradable. Therefore, the decomposition process of the polymer occurs in two stages: first, the molecules break up into small fragments by hydrolysis; and second, these fragments are biodegraded by microorganisms. In both stages, the presence of water is essential, both to chemically fragment the molecules, and to be consumed by microorganisms, that need much water in their cells.

To this group belong the aliphatic (i. e., non-aromatic) and the aliphatic-aromatic polyesters, described below. PCL can also be biodegraded directly by enzymes produced by microorganisms, without the initial stage of hydrolysis [24].

\subsection{Group of polyesters}

Polyesters are polymers in which the bonds between the monomers occur via ester groups. There are many types of natural esters, and their degrading enzymes - the esterases - are present everywhere, together with the living organisms. The ester bonds are generally easy to hydrolyze [20]. The group of biodegradable polyesters mainly consists of: a) linear aliphatic (i. e., non-aromatic) polyesters, such as polyglycolic acid (PGA) and poly ( $\varepsilon$ caprolactone) (PCL); b) aliphatic polyesters with short chain branching, such as polylactic acid (PLA), poly (3-hydroxybutyrate) (PHB) and poly(3-hydroxybutyrate-co-3-hydroxyvalerate) (PHBV), and c) aliphatic-aromatic polyesters such as poly(butylene succinate-coterephthalate) (PBST) and poly(butylene adipate-co-terephthalate) (PBAT).

\subsubsection{Poli(3-hydroxy-butyrate), or PHB, and copolymers}

Polyhydroxyalkanoates (PHAs) are polyesters of several hydroxyalkanoates that are synthesized by many microorganisms as a carbon and energy storage material. The hydroxyalkanoates can be synthesized from natural substances such as sucrose (e. g. from sugar cane), carboxylic acids and alcohols. Precisely for this reason, this material is rapidly biodegraded in various environmental conditions by many different organisms. Poly(R-3hydroxybutyrate) (PHB) is a homopolymer of R-3-hydroxybutyrate, and the best known polymer of the PHA group (Figura 2). The molecular weight generally varies from 50,000 to $2,000,000 \mathrm{~g} \cdot \mathrm{mol}^{-1}$. The monomers are all optical isomers $\mathrm{R}$, the only ones capable of being hydrolyzed by depolymerases, in the isotactic form [53].

PHAs polymers and copolymers are semicrystalline, with the molecules conformed in helices in the crystalline lamellae, which form spherulites. The native intracellular granules of PHAs with 0.2-0.7 $\mu \mathrm{m}$ in diameter, are amorphous and covered by a protein surface layer of about 2-4 nm, containing phospholipids. PHAs are attacked by intracellular PHAsdepolymerases enzymes, but not extracellular depolymerases [54, 55].

PHB is a biological storage material that is used by archaea, bacteria and fungi as feed source. There are more than 75 bacterial genera capable to synthesize PHAs, that are also produced by archaea, fungi, plants and animals, in the soils and aquatic bodies. In addition 
to the well known 3-hydroxybutyrate, more than 100 monomeric constituents have already been identified $[53,56]$.

Bacteria and archae can accumulate PHB up to about $95 \%$ by dry weight in their cells in the form of granules. The PHB synthesis can occur, for example, as follows: the bacteria are inoculated in a small batch reactor, along with sucrose, other nutrients and water, $\mathrm{pH}$ is adjusted and the temperature is raised. The growing colony is transferred to successively larger reactors. After the initial growth of bacteria, the competition period starts, with bacterial storage of PHB in the cytoplasm. The molecular weight increases continuously up to reactor cooling and addition of solvent, what will cause cell lysis and dissolve PHB, which is then purified and dried. The powder obtained in the extraction process is transformed into pellets in an extruder. At the same time nucleating agents and plasticizers are added to improve processability and mechanical properties.

There are also successful attempts to develop genetically modified plants to produce PHAs [40], but the products obtained are very expensive, not being accepted by the market.

As PHB is a very rigid and brittle polymer, it may be mixed with other polymeric materials that are softer and more strainable, such as PBAT or PCL. Blend-stabilizing copolymers, with an intermediate chemical structure, may be obtained by separated synthesis, by transesterification or by the action of peroxides on the two components. A significant product is the copolymer poly(3-hydroxybutyrate-co-3-hydroxy-valerate), or PHBV (Figure 2), which presents lower crystallinity and rigidity than $\mathrm{PHB}$, increasing the flexibility and the elongation capacity [57].

Some important PHAs manufacturers are Metabolix/ADM (Mirel and Mvera, $50 \mathrm{kt} / \mathrm{annum}$ ), Biomer, Tianan (PHBV, 1 kT/annum, being expanded) and PHB Industrial (60 t/annum pilot plant).

As for processing, the material depolymerizes at high temperatures, therefore the temperature of $185^{\circ} \mathrm{C}$ should not be exceeded. At $195{ }^{\circ} \mathrm{C}$ and up decomposition takes place, with emission of inflammable gases and darkening [58].

Some applications are: tubes for seedlings, injection and blown moulded containers, and films [for example, obtained with PHBH, or poly (3-hydroxybutyrate-co-3-hydroxy-hexanoate)].

For medical applications, the price of PHAs is already acceptable, although it is still too high for the commodity market, such as for packaging. Some important aspects to be improved in PHB are: strong degradation during processing ${ }^{1}$, excessive brittleness and low elongation capacity2. The latter can be solved through the use of copolymers and blends.

The PHAs may undergo simultaneously hydrolytic, oxidative and enzymatic degradation. The PHAs degrading microorganisms are widely distributed in the environment. Just as bacteria and archaea, fungi are also excellent decomposers [59].

\footnotetext{
${ }^{1} \mathrm{PHB}$ undergoes $\beta$-elimination reactions, which cleave molecules and form chains with terminal unsaturation [60].

${ }^{2}$ This is a consequence of the high crystallinity and the large spherulites formed, since the crystals nucleate slowly but grow fast.
} 
In addition to their high degradative potential, many fungi have remarkable capacity to expand on the substrate surface, surrounding it with their hyphae, which release extracellular enzymes close enough to achieve the substrate [59].

PHAs are biodegradable in windrow composting, soil or marine sediments. The enzymes which are involved in the degradation of PHAs are depolymerases, hydrolases which may be intra- or extracellular and endo- or exoenzymes ${ }^{3}$. They cleave the chain into smaller fragments (hydroxy acids), either monomers or oligomers, used as sources of carbon and energy ${ }^{4}$. The chains must be previously cleaved by extracellular depolymerases, then soluble monomers and oligomers are introduced and metabolized within the cells. Unlike the aquatic environment, the soil environment makes it difficult to transport the enzymes secreted by microorganisms over long distances to the substrate [59]. Biodegradation under aerobic conditions results mostly $\mathrm{CO}_{2}, \mathrm{H}_{2} \mathrm{O}$ and biomass, whereas, in anaerobic conditions, it results mainly, in addition to the above components, $\mathrm{CH}_{4}$ (methane). $\mathrm{PHB}$ is abiotically degraded by hydrolysis, with random cleavage of the ester linkages, especially at high temperatures (above $160-170{ }^{\circ} \mathrm{C}$ ). It is also biotically degraded by many genera of bacteria, archaea and fungi, with biofilm formation. The rate of biodegradation with PHA depolymerase is $10^{2}-10^{3}$ faster than that of hydrolytic degradation. The degradation of the amorphous regions is faster than that of the crystalline regions. In the PHBV copolymer, the crystallinity maintained constant, the addition of 3-hydroxy-valerate decreases the hydrolysis rate, as well as the enzymatic degradation rate. Longer side chains on the $\beta$ carbon further reduce the possibility of enzymatic attack [53].

\subsubsection{Poly(E-caprolactone) or poly(6-hydroxy-hexanoate) (PCL)}

PCL is a biodegradable polyester obtained from raw materials originating from petroleum, through ring opening polymerization of the lactone with suitable catalysts (Figure 2).

It has good resistance to water and organic solvents. PCL is a polymer stable against abiotic hydrolysis, which occurs slowly with molecular weight decrease. Its melting temperature is low, as its viscosity, facilitating its thermal processing. PCL may present spherulitic structure. It is a soft and flexible polymer, that may be used in blends with other biodegradable polymers, such as starch.

A major global manufacturer is Solvay (Capa, 5,000 t per year). Some applications are foamed food trays, bags, bioabsorbable medical items, replacement of gypsum in the treatment of broken bones, etc.

PCL may be degraded by many microorganisms, including bacteria and fungi, that are spread by soils and water bodies [56]. However, an initial stage of abiotic hydrolysis appears to be necessary [61]. The rates of hydrolysis and biodegradation depend on

\footnotetext{
${ }^{3}$ The enzymes may be classified as intra- or extracellular according their action inside or outside the cell, and also as endo- or exoenzymes, according their action inside or at the end of the substrate molecule.

${ }^{4}$ They are usually induced enzymes whose expression is repressed in the presence of other carbon sources such as glucose and organic acids.
} 
molecular weight and crystallinity [40]. Pronounced biodegradation occurs with molecular weights below about 5,000 g-mol ${ }^{-1}$. Abiotic and biotic degradation take place preferentially in the amorphous phase. Certain PCL-depolymerases, such as Pseudomonas lipase, can hydrolyse both amorphous and crystalline PCL phases. Enzymes from the two major classes of excreted esterases - lipases and cutinases - are able to degrade PCL and its blends [62]. Biodegradation causes surface erosion, without reduction of molecular weight [54].

\subsubsection{Polylactic Acid (PLA)}

PLA is an aliphatic polyester, derived from renewable resources, e. g. corn starch or sugarcane sucrose. It is a polymer produced from lactic acid (Figure 2), which is obtained from the fermentation of various carbohydrate species: glucose, maltose and dextrose from corn or potato starch; sucrose from beet or sugar cane; and lactose from cheese whey [63].

Lactic acid is chiral and has two isomers: the (S)-lactic acid (or L-(+)-lactic acid) and the (R)lactic acid (ou D-(-)-lactic acid). The lactic acid monomer may be obtained by fermenting carbohydrate crops such as corn, sugar cane, cassava, wheat and barley, being eventually converted to lactide by means of a combined process of oligomerization and cyclization, with the use of catalysts. The synthesis of PLA (polylactate) was explored by Cargill, Hycail, Neste Oy, Shimadzu and Mitsui. Mitsui used a solvent based process to remove water azeotropically in the condensation polymerization process. Neste has obtained high molecular weight PLLA (i. e., L-PLA, or PLA from L-lactic acid) by joining low molecular weight precursors through urethane links. All the others use the dimer lactide process, with lactide ring opening polymerization. In the process using lactides, the additional step of dimerization of lactic acid increases production costs, but improves the control of molecular weight and end groups of the final polymer [38].

Lactic acid in the $\mathrm{L}$ isomeric form may be obtained by fermentation of glucose, while the lactic acid obtained via petrochemistry is in the racemic form $(\mathrm{L} / \mathrm{D}=1)$. Through the stereochemical control of lactic acid (ratio of D- and L- optical isomers), one can vary the crystallinity of PLA and also rate of crystallization, transparency, physical properties and even the biodegradation rate. For example, poly(L-lactide), or L-PLA is a semicrystalline polymer with glass transition temperature of $76^{\circ} \mathrm{C}$ and melting at $180{ }^{\circ} \mathrm{C}$, while poly(DLlactide), or DL-PLA, is an amorphous polymer with glass transition at $58^{\circ} \mathrm{C}$ [64). DL-PLA is used when it is important to have a homogeneous dispersion of the active species in the single-phase matrix, such as in devices for controlled release of drugs (in the same manner that PLAGA copolymers). L-PLA is preferred for applications where mechanical strength and toughness are required, such as in sutures and orthopedic appliances.

The mechanical properties are somewhat higher than those of polyolefins in general. PLA is a hard material, similar in hardness to acrylics (as methyl methacrylate). Because of its hardness, PLA fractures along the edges, resulting in a product that cannot be used. To overcome these limitations, PLA must be compounded with other materials to adjust the hardness [65]. 
The low glass transition temperature (see Table 2) is the reason for the limited resistance of PLA to heat, making PLA inadequate for hot drink cups, for example. PLA is suitable for frozen food or for packages stored at ambient temperatures.

PLA have been used in films for packaging, thermoformed and injection moulded disposable rigid containers (for example, food containers and trays), blown flasks and bottles, filaments, and biomedical uses (capsules for drug delivery, fibers for tissues and absorbable/degradable surgical sutures, and internal bone fixation implants). It is a polymer with consolidated use in the medical area, due to its biocompatibility and biodegradability in the human body. PLA-based resins may be modified to adapt to many applications, from disposable food-service items to sheet extrusion, and coating for paper [40].

Some of the leading manufacturers of PLA are: NatureWorks (Ingeo, capacity of $140 \mathrm{kt}$ per annum), Teijin (BioFront, 1-5 tons per annum, Hisun Biomaterials (5,000 t per annum), Purac/Sulzer/Synbra, SK Chemicals, Biotech, Futerro, Mitsui Toatsu and Shimazu

The abiotic degradation of PLA takes place in two stages: a) diffusion of water through the amorphous phase, degrading that phase; and b) hydrolysis of crystalline domains, from the surface to the center [61]. The ester linkages are broken randomly. A semicrystalline material such as poly(L-lactate) presents a hydrolysis rate much lower than that from an amorphous material, such as poly (D,L-lactate), with half-lives of, respectively, one or a few years, and a few weeks. The hydrolysis is self-catalyzed by the acidity of the resulting carboxylic groups [66].

PLA can not directly be degraded by microorganisms, but requires first abiotic hydrolytic degradation, so that the microorganisms (mainly bacteria and fungi, which form biofilm) can metabolize the lactic acid and its oligomers dissolved in water. Abiotic hydrolysis takes place at temperatures above the glass transition temperature, i. e., at temperatures above $55{ }^{\circ} \mathrm{C}$. Thus PLA is fully biodegradable in composting conditions of municipal waste plants, although it may need a few months to several years to be degraded under conditions of home composting, soil or oceans [35, 63, 67]. Furthermore, the PLA degrading microorganisms are not widespread in the environment $[20,61,67]$.

The polymer passes the tests of compostability, provided that the thickness of the parts do not exceed around 2-3 mm. The extracellular enzymatic degradation consists of two steps: a) the enzyme is adsorbed on the polymer surface, through its binding site; and b) ester bonds are cleaved through the catalytic site of the enzyme [61]. The polymer chain ends are attacked preferentially. The biodegradation rate is a function of the crystallinity and the content of L-monomers [68]. Some enzymes (proteases) that may degrade PLA are proteinase $\mathrm{K}$, pronase and bromelain. Subtilisin, a microbial serine protease, and some mammalian serine proteases, such as $\alpha$-chymotrypsin, trypsin and elastase, could also degrade PLA [20, 61, 67].

\subsubsection{Polyglycolic Acid (PGA)}

It is the simplest linear polyester, consisting only of a methylenic group between the ester linkages. It may be synthesized in a way quite similar to that of PLA, by the ring opening 
polymerization of glycolide, that is the cyclic dimer of glycolic acid. The glass transition temperature of the homopolymer is about $35-40{ }^{\circ} \mathrm{C}$ and the melting temperature is about $225-230{ }^{\circ} \mathrm{C}$. Glycolate is copolymerized with lactate in order to obtain a copolymer with appropriate stiffness and elongation capacity (known as PLAGA).

Among the manufacturers are American Cyanamid (Dexon), DuPont (Vicryl) and Kureha (Kuredux). The biodegradation of the PGA is usually faster than that of PLA, although an initial stage of abiotic hydrolysis appears to be necessary, since the polymer has a phase in the crystalline state and another in the amorphous glassy state [61].

PGA and its copolymers with lactic acid have very important medical applications: body absorbable sutures; ligaments reestablishment, through resorbable plates and screws; drugs of controlled release; grafting of arteries; etc. Although the homopolymers PGA and D-PLA are not biodegradable, copolymers of glycolic acid and D-lactic acid, which may still contain L-lactic acid, are usually biodegradable by lipase enzymes [67]. The degradation of PGA seems to follow the same steps of PLA: diffusion of water into the amorphous region, with degradation and erosion; hydrolytic attack of the crystalline region; and biodegradation of monomers and oligomers dissolved in water.

\subsubsection{Aliphatic-aromatic polyesters}

The aliphatic-aromatic polyesters have petrochemical origin, and are generally produced through traditional polycondensation reactions. The structure of two of them, PBAT and PBST, may be seen in Figure 2. They consist of aliphatic chain segments (residues of 1,4butanediol, and of adipic or succinic acid), which provide flexibility, toughness, and biodegradability and aromatic segments (residues of terephthalic acid and 1,4-butanediol), which impart mechanical strength and rigidity. PET, an aromatic polyester, decomposes very slowly in recalcitrant aromatic oligomers [69].

The degradation of the aliphatic-aromatic polymers may be oxidative, hydrolytic and enzymatic. The oxidative degradation occurs in the presence of oxygen gas and heat, ultraviolet radiation and/or mechanical stresses. The hydrolytic degradation occurs in presence of water, and is self-catalyzed by the acidity of the carboxylic acids, being more intense inside the part. The enzymatic hydrolysis uses non-specific enzymes, such as hydrolases and lipases, produced by an enormous variety of organisms, especially the mycelium-forming microorganisms (fungi and actinomycetes) [69]. The amorphous regions are degraded preferentially over the crystalline regions, both chemically and biologically. Interestingly, there is an inverse relationship between the melting temperature of the polyester and its rate of biodegradation, indicating that the crystalline characteristics are a very important factor in its biodegradability [69, 70]. The polyesters that behave like elastomers at the degradation temperature, undergo enzymatic degradation from the moment in which they are placed in the disposal environment, showing surface erosion. The polyesters that behave like glass at the degradation temperature are enzymatically degraded only at the end of the degradation process, from the by-products of the preliminary abiotic 
degradation. Although the aliphatic-aromatic polyesters present high degradability in industrial composting, their rate of degradation in soil and water bodies is much lower, and their degradability under anaerobic conditions is even lower [69].

Some applications are the same typical for LDPE: transparent blown films, mulch films for agriculture, films for package and bags, and also blown bottles, filaments, injection moulded and thermoformed products [69].

Poly(butylene adipate-co-terephthalate) (PBAT): Some of its main applications are films (mulch, containers, bags), filaments, thermoformed and injection moulded products, and blown bottles. Two products in the market are Ecoflex (BASF, 14,000 t per year) and MaterBi (former EasterBio/Eastman, now Novamont, 15,000 t per year). For some applications, PBAT has a very low stiffness, and may be mixed with PHB or PLA, for example. It may also be mixed with thermoplastic starch $[69,71]$.

Poly(butylene succinate-co-terephthalate (PBST): Some of its main applications are blown films, filaments, blown and injection moulded containers, thermoformable cups and trays, paper coating, etc. A product in the market is Sorona/Biomax). PBST has good mechanical properties, reasonable processing and biodegrades slowly [69, 72].

\subsection{Standards for biodegradation tests - hydrobiodegradable and inherently biodegradable polymers}

There is not a standard test of biodegradability of universal validity. For the hydrobiodegradable and inherently biodegradable polymers, it is common the use of patterns for testing compostability. Some standards for compostability are: EN 13432, ASTM D6400, ASTM D5338, ISO 14855 and 17088, and Australian Standard 4736. These are standards for biodegradation in the special conditions found in industrial composting, that require short timescales and rapid $\mathrm{CO}_{2}$ emissions. There are also standards for biodegradation in soils and aquatic environments but they are less used.

Finally, the third group of biodegradable polymers consists of oxo-biodegradable materials, that is, those that need to undergo the chemical process of oxidation (combination with oxygen, which leads to breakage of the molecules) before they become biodegradable. In general, all the traditional widely used plastic materials are oxo-biodegradable, that is, over time undergo oxidative degradation, what leads to the breakdown of their molecules into smaller fragments, highly oxygenated, capable of being biodegraded. However the time scale to complete degradation and biodegradation is too long: it takes several decades [25, $26,73]$. To accelerate this process, organic salts (such as stearates) of transition metals (such as iron, manganese and cobalt) are added, so reducing the time required for degradation and biodegradation to some years [74]. Such additives are known as pro-oxidants or prodegrading. Until now, these salts have shown no toxicity to animals, plants or microorganisms, being rather micronutrients to them. To this group belong lignin, lignocellulose, natural rubber and polybutadiene (without the need of pro-oxidant 
additives) as well as traditional plastics, such as polyethylene, polypropylene, polystyrene and PET, all these formulated with pro-oxidant additives.

\subsection{Oxo-biodegradable polymers}

Oxo-biodegradable polymers are the polymer materials that present in their formulation pro-oxidant and antioxidant additives, so as to provide a planned period of useful life, after which the materials begin to degrade oxidatively, the residues being inherently biodegradable. It is also possible that the polymer contains pro-oxidant chemical structures, such as double bonds and atoms susceptible to attack by free radicals. The oxidation process is called peroxidation, and occurs through a free radical mechanism [1]. The first step is the formation of a free radical in the polymer (i. e., a macrorradical), through the homolytic cleavage of a $\mathrm{CH}$ or a $\mathrm{CC}$ bond, that could take place because of the heat, the UV radiation or the mechanical stress (e. g., shear or elongation during the processing of the material, or the wind or ocean waves action). Then the polymer radical formed may capture an oxygen molecule, generating a peroxide radical, which after capturing a hydrogen atom bound to the polymer will form a hydroperoxide bond. The hydroperoxide decomposes over time, generating an alkoxy and a hydroxyl radical. The decomposition can be accelerated by about $10^{2}$ times with the use of catalysts based on organic salts of Fe, Mn, Co, etc [27, 28]. These salts also help to carry oxygen to the polymer molecules. The hydroxyl radical may capture hydrogen atoms, generating new macrorradicais. The alkoxy radical can recombine, generating a ketone group, or breaking the molecule, generating a new radical. The ketone group is susceptible to degradation by UV, which can cause rupture of the chain, by the mechanisms of Norish I and II. The free radical reactions involving organic polymer and oxygen generate many different molecules, which may contain the groups hydroxyl, carbonyl, ether, ester, carboxyl, etc., and also insaturations [25, 26]. Therefore, the final product from the polymer abiotic degradation generally consists of small and strongly oxygenated molecules, capable of crossing the cell wall (if present) and membrane, and that are metabolyzed in the cytoplasm of microorganisms with the help of the available enzymes, which depend on the chemical structure of the oligomers and the genetic potential of the organism [4].

The antioxidant additives present in the formulation of a polymer resin may have the function of protecting it against degradation by deactivating the free radicals formed (primary antioxidants) or by decomposing hydroperoxides formed (secondary antioxidants). The former are useful during the service life of the material at ambient temperatures, whereas the latter are most useful when processing the material at elevated temperatures [75].

Molecular weight reduction is generally a consequence of oxidative degradation (being e. $\mathrm{g}$. the case of PE, PP and PS), what causes the collapse of the mechanical properties, and consequent disintegration (fragmentation) of the part [27, 28, 76]. Oxidative degradation also causes the incorporation of oxygen atoms in the chains and the rise of double bonds. The 
residue from abiotic degradation of a plastic material is no longer plastic, but a complex mixture of unsaturated and oxygenated oligomers, showing some hydrophilicity and being biodegradable by a large number of genera of naturally occurring microorganisms [25, 26, 28].

\begin{tabular}{lccccccc}
\hline \multirow{2}{*}{ Characteristics } & \multicolumn{7}{c}{ Days of exposure } \\
\cline { 2 - 8 } & $\mathbf{0}$ & $\mathbf{5 4}$ & $\mathbf{8 0}$ & $\mathbf{1 3 6}$ & $\mathbf{1 9 0}$ & $\mathbf{2 4 2}$ & $\mathbf{2 9 9}$ \\
\hline Average molar mass $^{\mathbf{a}}$ & 10500 & 10700 & 8630 & 3450 & 3310 & 3300 & 2620 \\
Mn, g mol $^{-1}$ & 183000 & 112000 & 80500 & 13000 & 15000 & 9210 & 7850 \\
Mw, g mol $^{-1}$ & 17.43 & 10.47 & 9.33 & 3.77 & 4.53 & 2.79 & 3.00 \\
Polydispersity (Mw/Mn) $_{\text {Carbonyl index }}^{\mathbf{b}}$ & 0.000 & - & 0.187 & 0.427 & 0.580 & 0.675 & - \\
Degree of crystallinity (\%) $^{\mathbf{c}}$ & 58 & 59 & - & 63 & 66 & 70 & - \\
Mechanical properties $^{\mathbf{d}}$ & & & & & & & \\
Stress at fracture (MPa) & $52 \pm 4$ & $29 \pm 6$ & $16 \pm 2$ & 0 & 0 & 0 & 0 \\
Strain at fracture (\%) & $400 \pm 40$ & $230 \pm 40$ & $60 \pm 9$ & 0 & 0 & 0 & 0 \\
\hline
\end{tabular}

a From SEC. Mn, Mw = number and weight average molar masses, respectively.

${ }^{\mathrm{b}}$ From FTIR spectroscopy.

c From DSC, second heating runs.

d From tension tests. Values expressed with their standard errors.

Table 3. Characteristics of oxo-biodegradable polyethylene films subjected to weathering for different periods of time [28].

In Table 3, it is possible to observe the changes in molecular weight and carbonyl concentration, as well as the consequent changes in mechanical properties, that occur with the outdoor weathering of films of a HDPE/LDPE blend for several months. The increase in crystallinity can be explained by the higher freedom of motion of smaller polymer chains, that could be rearranged in more crystalline structures [28].

The rates of biodegradation of the residues from oxo-biodegradable materials are usually lower than those of most hydro-biodegradable materials. It generally takes a few years to quantitative biodegradation of the oxo-bio materials, depending on resin type, environmental conditions and formulation of additives used. Figure 3 shows the mineralization curves for an oxo-biodegradable HDPE/LLDPE blend biodegraded in composting conditions at two different temperatures.

After a certain level of oxidative degradation, biofilms can be observed on the oxidized polymer residues [25-27]. These biofilms mainly consist of fungi and bacteria, although archaea, algae and protozoa may also be present. The oxo-bio materials may be recycled with conventional polymer materials, provided that the resins still contain antioxidant additives in concentration sufficient to prevent oxidative degradation during processing and service life. Some people consider that the residues of oxo-biodegradable polymers contain toxic metals, but so far there is no evidence of toxicity of them to plants or animals. Instead, the cations of $\mathrm{Fe}, \mathrm{Co}$ and $\mathrm{Mn}$ are micronutrients, acting as cofactors of enzymes. At very high concentrations, these cations may damage the plants, even because they increase the osmotic pressure of the environment and may dehydrate the root cells. 
Conventional materials, such as polyolefins and polystyrene, can be converted to oxobiodegradable materials by adding 1-5\% (typically) of additives, what tend to increase the total cost of the resin in 5-15\%. Some of the leading manufacturers of oxo-bio additives are Symphony Environmental ( $\left.\mathrm{d}_{2} \mathrm{w}\right)$, EPI (TDPA), Wells (reverse), Willow Ridge (PDQ) and others.

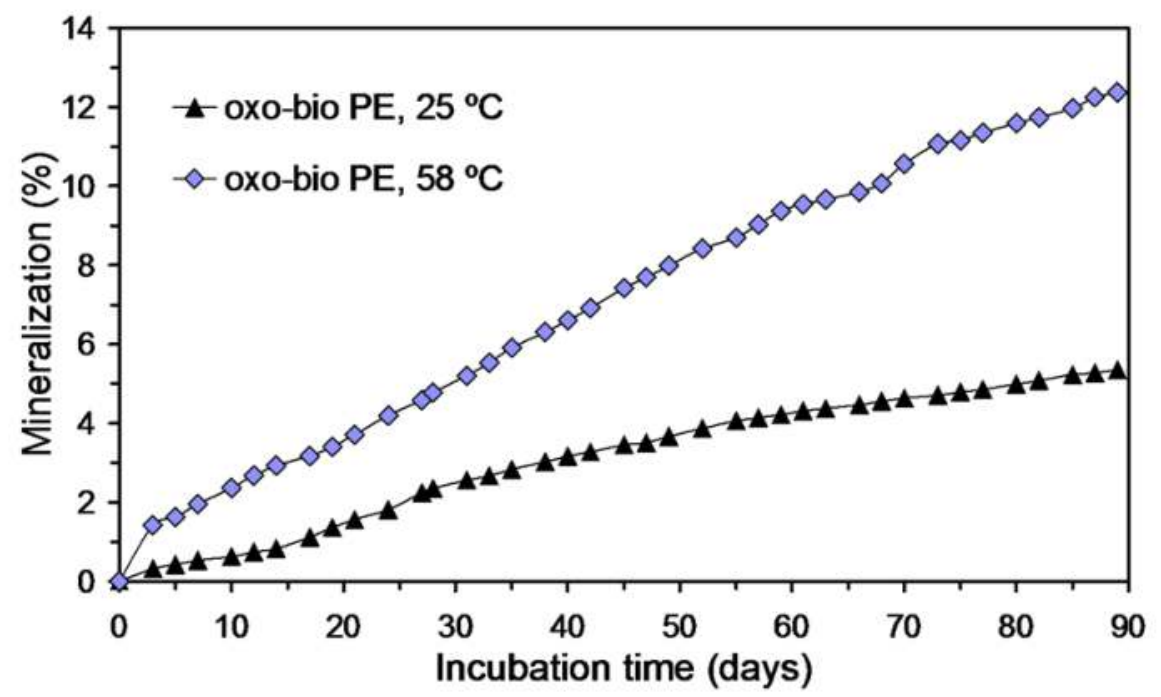

Figure 3. Biodegradation of polyethylene films as a function of incubation time at 25 and $58{ }^{\circ} \mathrm{C}$ in compost/perlite, at $50 \%$ relative humidity [28].

\subsection{Standards for biodegradation tests - oxo-biodegradable polymers}

Standards for slowly biodegradable products are a challenge, because it becomes very difficult to simulate in a laboratory the biodegradation that takes place in real environments. In laboratory microcosms, the environment is isolated, without the possibility of free mass exchange with the surroundings. So there may be accumulation of metabolites produced by microorganisms, to the point where they become toxic and disrupt microbial growth. Thus, it is possible that only the beginning of biodegradation can be observed, but this does not mean that biodegradation would be interrupted in real conditions.

It is not possible to provide a specific timescale in a general standard for oxo-biodegradable polymers, (as distinct from a standard for industrial composting) because the conditions found in industrial composting are specific and the conditions found in the open environment are variable. Also, the time taken for oxo-biodegradable plastic to commence and complete the processes of degradation and biodegradation can be varied. 
Some standards for the analysis of oxo-biodegradable products are: ASTM 6954-04 (USA), BS8472 (UK), SPCR 141 (Sweden) and UAE standard 5009:2009 (United Arab Emirates). They usually require three test levels: 1 ) abiotic degradability (decrease of molecular weight and mechanical properties, low gel formation); 2) biodegradability (biofilm formation, release of $\mathrm{CO}_{2}$, tested with the residue obtained at level 1); and 3) ecotoxicity (to animals, plants and microorganisms) of the residues from levels 1 and 2. The ecotoxicity tests may follow the OECD standards, for example, to algae (OECD 201), microcrustaceans (OECD 202), fish (OECD 203), earthworms (OECD 207) and plants (OECD 208). A highly sensitive method for measuring low rates of biodegradation was developed by Chiellini et al. [77], and used with modifications by Fontanella et al. [27] and Ojeda et al. [28].

\subsection{Blends}

In order to maintain a good compromise among biodegradability, chemical and physical properties, and costs, mixtures or blends of polymers of any of the three groups mentioned above (i.e., inherently, hydro- and oxo-biodegradable polymers) have appeared on the market. Some biodegradable polymers are very rigid and brittle (e. g., PHB and PLA), while others are very soft and flexible (e. g., PCL and PBAT). The mixture (blend) of two or more different polymers may lead to a blend of interesting intermediate mechanical properties. The processability of the final material may also be improved, included here the resistance to chemical decomposition during processing, among other features. Examples of commercial blends are: modified starch + PBAT (e. g., Novamont - MaterBi; Corn Products/Basf - Ecobras) for films, thermoformed and injection moulded parts; PBAT + PLA (e. g., BASF - Ecovio) for films, thermoformed and extruded parts; PLA + starch (e. g., Cereplast - Cereplast Compostables) for bags and packaging, injection moulded and extruded articles for food, pens, etc.

\section{Non-biodegradable polymers derived from renewable resources}

Some polymer materials are produced wholly or partly from renewable (the term renewable here is very limited, as was previously explained) raw materials. Some examples are listed below.

Braskem - green polyethylene: is the traditional polyethylene, but derived from ethylene produced with ethanol from sugar cane. DuPont - PTT - poly(trimethylene terephthalate): one of its monomers, 1,3-propanediol, is obtained from corn or sugar beets. Coca-Cola Co: PlantBottle: PET bottle made from ethylene glycol obtained from alcohol derived from sugar cane and molasses. In addition, the PP cap is slightly smaller. The proportion of raw materials obtained from fossil fuels (oil, coal and gas) and obtained from plants can be found through analysis of the proportion of carbon-12 to carbon-14 present in the polymer, since fossil fuels contain virtually no carbon-14 whose half-life is about 5730 years (see ASTM D6866-11). 


\section{Conclusion - Future perspectives of environmental friendly polymer materials}

The environmental impacts produced by conventional polymers on the planet are now clearly observed. As a consequence, these materials, especially plastic bags, have suffered many attacks in several countries, and alternative solutions to their use have been encouraged. However, to date, no definitive and universal solution for the replacement of conventional polymer materials has emerged. And it is very likely that the path to be taken is exactly this: to promote the diversity of materials available, according to the local diversities of the planet. Depending on environmental conditions, available raw materials, local cultures, industrial parks, etc., different polymeric or not polymeric materials may be elected as the most appropriate for a given population at a given time in history. The effects of globalization and the current facility of transportation from a continent to another can not be neglected.

The continuous worldwide implementation of renewable forms of energy might permit the use of petroleum as a petrochemical feedstock for many more years. However, mechanical, chemical and energy recovery would need to be improved greatly, and the products difficult to recycle should be mixed with pro-oxidant additives. Another interesting solution is the production of biodegradable polymer materials from agricultural and other organic wastes, such as PHAs produced from stover. Anyway, composting units should be encouraged in all countries around the world.

\section{Author details}

Telmo Ojeda

Environmental Sciences - Federal Institute for Education, Science and Technology (IFRS) - Porto Alegre, Brazil

\section{References}

[1] Scott G (1999) Polymer and the environment. Cambridge: RSC Paperbacks. 132p.

[2] Stevens ES (2003) What makes green plastics green? BioCycle 24: 24-27

[3] Al-Salem SM, Lettieri P, Baeyens J (2009) Recycling and recovery routes of plastic solid waste (PSW): a review. Waste management 29: 2625-2643.

[4] Atlas RM, Bartha R (1998) Microbial ecology: fundamentals and applications, 4th. Menlo Park: Benjamin/Cummings. 694p.

[5] Edwards C, Fry JM (2011) Life Cycle Assessment of Supermarket Carrier Bags. Environmental Agency, Bristol, UK. Available: http://www.biodeg.org/files/ uploaded/Carrier_Bags_Report_EA.pdf. Accessed 2012 May 25.

[6] James K, Grant T. LCA of degradable plastic bags. Centre for design at RMIT university. Available: www.europeanplasticfilms.eu/docs/Jamesandgrant1.pdf. Acessed 2012 May 25. 
[7] Tabone MD et al. (2010) Sustainability metrics: life cycle assessment and green design in polymers. Environ Sci Technol. 44:8264-8269.

[8] Scott G. (2002) Why biodegradable polymers? In: Scott G, editor. Degradable polymers. Dordrecht/Boston/London: Kluwer Academic Publishers. pp. 1-15.

[9] Thornton J (2002) Environmental impacts of polyvinyl chloride building materials. Healthy building network. Available: http://www.healthybuilding.net/pvc/ Thornton_Enviro_Impacts_of_PVC.pdf. Acessed 2012 May 25.

[10] Titow WV (1984) PVC technology, 4th. ed., Elsevier. pp. 263-286.

[11] Okada $\mathrm{H}$ et al. (2008) Direct evidence revealing structural elements essential for the high binding ability of bisphenol A to human estrogen-related receptor-gamma. Environ. Health Perspect. 116(1):32-38.

[12] Vom Saal S, Myers JP (2008) Bisphenol A and risk of metabolic disorders. JAMA. 300(11):1353-1355.

[13] Vogel S (2009) The politics of plastics: the making and unmaking of bisphenol A' safety. American journal of publich health 99(S3):559-566.

[14] Ogiue-Ikeda M et al. (2008) Rapid modulation of synaptic plasticity by estrogens as well as endocrine disrupter in hippocampal neurons. Brain research reviews 57(2):363-375.

[15] Soto AM, Sonnenschein C (2010) Environmental causes of cancer: endocrine disruptors as carcinogens. Nature Reviews Endocrinology 6 (7): 363-370.

[16] Yanagiba $Y$ et al. (2008) Styrene trimer may increase thryroid hormone levels via downregulation of the aryl hydrocarabon receptor (AhR) target gene UDPglucuronosyltransferase. Environmental health perspectives 116(6):740-745.

[17] Schumann H-D, Thiele UK (1996) Polyester producing plants - principles and technology. Landsberg/Lech: Moderne Industrie. 72 p.

[18] Mark JE (1999) Polymer data handbook, Oxford: Oxford University Press. 1012 p.

[19] Alexander M (1973) Nonbiodegradable and other recalcitrant molecules. Biotechnology and bioengineering. 15: 611-647.

[20] Shimao M (2001) Biodegradation of plastics. Current opinion in biotechnology. 12: 242247.

[21] Gugumus F (1992) Stabilization of plastics against thermal oxidation. In: Gächter H, Müller F, editors. Plastics additives handbook, 3rd ed. Munich: Hanser Publishers.

[22] Nakajima-Kambe $\mathrm{T}$ et al. (1999) Microbial degradation of polyurethane, polyester polyurethanes and polyether polyurethanes. Applied microbiology and biotechnology. 51(2): 134-140.

[23] Scott G, Wiles DM (2001) Programmed-life plastics from polyolefins: a new look at sustainability. Biomacromolecules. 2(3): 615-622.

[24] Scott G (1997) Abiotic control of polymer biodegradation. Trip. 5(11): 361-368.

[25] Khabbaz F, Albertsson A-C, Karlsson S (1999) Chemical and morphological changes of environmentally degradable polyethylene films exposed to thermo-oxidation. Polymer degradation and stability. 63:127-138.

[26] Albertsson A-C et al. (1995) Degradation product pattern and morphology changes as means to differentiate abiotically and biotically aged degradable polyethylene. Polymer. 36(16): 3075-3083. 
[27] Fontanella S et al. (2010) Comparison of the biodegradability of various polyethylene films containing pro-oxidant additives. Polymer degradation and stability. 95: 10111021.

[28] Ojeda TFM et al. (2009) Abiotic and biotic degradation of oxo-biodegradable polyethylenes. Polymer degradation and stability. 94: 965-970.

[29] Azapagic A, Emsley A, Hamerton I. (2003) Polymers: the environment and sustainable development. Wiley. pp. 22-23.

[30] Valle MLM et al. (2004) Degradação de poliolefinas utilizando catalisadores zeolíticos. Polímeros: ciência e tecnologia. 14: 17-21.

[31] Jacques RJS et al. (2005) Anthracene biodegradation by Pseudomonas sp. isolated from a petrochemical sludge landfarming site. International biodeterioration \& biodegradation 56: 143-150.

[32] Bastioli C (2004) Starch-polymer composites. In: Scott G, editor. Degradable polymers. Dordrecht/Boston/London: Kluwer academic publishers. pp. 133-161.

[33] Lu DR, Xiao CM, Xu SJ (2009) Starch-based completely biodegradable polymer materials. Express polymer letter. 3(6): 366-375.

[34] Bastioli C (2005) Starch-based technology. In: Bastioli C, editor. Handbook of biodegradable polymers. Shawbury, Shrewsbury, Shropshire: Rapra Technology. pp.257-286.

[35] Australian government - department of the environment, water, heritage and the arts. Degradable plastics. Available: http://www.environment.gov.au/settlements/ publications/waste/degradables/biodegradable exec-summary.htm). Accessed: 2012 May 25.

[36] Nakamura EM et al. (2005) Study and development of LDPE/starch partially biodegradable compounds. Journal of materials processing technology. (162-163): 236241.

[37] Erlandsson B, Karlsson S, Albertsson A.-C (1997) The mode of action of corn starch and pro-oxidant system in LDPE: influence of thermo-oxidation and UV-irradiation on the molecular weight changes. Polymer degradation and stability. 55: 237-245.

[38] Chiellini E, Chiellini F, Cinelli P (2002) Polymers from renewable resources. In: Scott, G, editor. Degradable polymers. Dordrecht/Boston/London: Kluwer. pp. 165-178.

[39] Lynd RL et al. Microbial cellulose utilization: fundamentals and biotechnology. Microbiology and molecular biology reviews. 66(3): 506-577.

[40] Gross RA, Kalra B (2002) Biodegradable polymers for the environment. Science. 297: 803-807.

[41] Piskin E (2002) Biodegradable polymers in medicine. In: Scott G, editor. Degradable polymers, Dordrecht/Boston/London: Kluwer Academic. pp. 347-349.

[42] Chandra R, Rustgi R (1998) Biodegradable polymers. Prog. Polym. Sci. 23: 1273-1335.

[43] Martone PT et al. (2009) Discovery of lignin in seaweed reveals convergent evolution of cell-wall architecture. Current biology. 19(2): 169-75.

[44] Sjöström E (1993) Wood chemistry: fundamentals and applications. Academic Press. (ISBN 0-12-647480-X)

[45] Boerjan W, Ralph J, Baucher M (2003) Lignin bios. Ann. rev. plant biol. 54(1):519-549. 
[46] Tuomela et al. (2000) Biodegradation of lignin in a compost environment: a review. Bioresource technology. 72(2): 169-183.

[47] Tecnaro - Arboform. Available: http://www.tecnaro.de/english/arboform.htm. Accessed: 2012 May 25.

[48] Slater S et al. (2004) Evaluating the environmental impact of biopolymers. In: Steinbüchel A, editor. Biopolymers, v. 10. Wiley Interscience. pp. 473-480.

[49] Vinyl alcohol polymers. Encyclopedia of polymer science and technology, John Wiley \& Sons, v.8, p.399-436.

[50] Rudnik E (2008) Compostable polymer materials. Elsevier. 211p.

[51] Swift G (2002) Environmentally biodegradable water-soluble polymers. In: Scott, G. Degradable polymers - principles and applications, Kluwer Academic Publishers. pp. 379-412.

[52] Yubin LV et al. (2011) Research development of biodegradable modification of poly(vinyl alcohol) film. Advanced materials research. 380: 234-237.

[53] Reddy CSK, Ghai R, Rashami, Kalia VC (2003) Polyhydroxyalkanoates: an overview. Bioresource technology. 87: 137-146.

[54] Jendrossek D (2001) Microbial degradation of polyesters, Advances in biochemical engineering/biotechnology. 71: 293-325.

[55] Braunegg G (2002) Sustainable poly(hydroxyalkanoate) (PHA) production. In: Scott G, editor. Degradable polymers - principles and applications. Dordrecht/Boston/London: Kluwer Academic Publishers. pp. 235-293.

[56] Suyama T et al. (1998) Phylogenetic affiliation of soil bacteria that degrade aliphatic polyesters available commercially as biodegradable plastics. Applied and environmental microbiology. 64(12): 5008-5011.

[57] Sudesh K, Doi Y (2005) Polyhydroxyalkanoates. In: Bastioli C, editor. Handbook of biodegradable polymers. Shawbury, Shrewsbury, Shropshire: Rapra Technology. pp. 219-256.

[58] Biomer biopolyesters. Available: http://www.biomer.de. Accessed: 2012 May 25.

[59] Sang BI, Hori K, Unno H (2002) Fungal contribution to in situ biodegradation of poly(3hydroxybutyrate-co-3-hydroxyvalerate) film in soil. Appl. microbiol. biotechnol. 58: 241-247.

[60] Chodak I (2002) Polyhydroxyalkanoates: properties and modification for high volume applications. In: Scott G, editor. Degradable polymers - principles and applications. Dordrecht/Boston/London: Kluwer Academic Publishers. pp. 295-319.

[61] Li S, Vert M (2002) Biodegradation of aliphatic polyesters. In: Scott, G. Degradable polymers - principles and applications. Dordrecht/Boston/London: Kluwer Academic Publishers. pp. 71-131.

[62] Tucker N, Johnson M, editors (2004) Low environmental impact polymers, UK: Rapra. 360p.

[63] Garlotta DA (2001) Literature review of poly(lactic acid). Journal of polymers and the environment. 9(2): 2001.

[64] Reeve MS et al. (1994) Polylactide stereochemistry: effect on enzymatic degradability. Macromolecules. 27: 825-831. 
[65] Briassoulis D (2004) An overview on the mechanical behaviour of biodegradable agricultural films. Journal of polymers and the environment. 12(2): 65-81.

[66] Hakkarainen M (2002) Aliphatic polyesters: abiotic and biotic degradation and degradation products. Advances in polymer science. 157: 113-138.

[67] Tokiwa Y et al. (2009) Biodegradability of plastics. International journal of molecular sciences. 10: 3722-3742.

[68] Auras R, Lim L-T (2010) Poly(lactic acid): synthesis, structures, properties, processing and applications. Wiley, 2010.

[69] Müller R-J (2005) Aliphatic-aromatic polyester. In: Bastioli C, editor. Handbook of biodegradable polymers. UK: Rapra Technology. pp. 303-337.

[70] Marten E, Müller R-J, Deckwer W-D (2005) Studies on the enzymatic hydrolysis of polyesters. II. Aliphatic-aromatic copolyesters. Polymer degradation and stability. 88(3): 371-381.

[71] Witt U et al. (2001) Biodegradation of aliphatic-aromatic copolyesters: evaluation of the final biodegradability and ecotoxicological impact of degradation intermediates. Chemosphere 44: 289-299.

[72] Ki HC, Park OO (2001) Synthesis, characterization and biodegradability of the biodegradabale aliphatic-aromatic random copolyesters. Polymer 42: 1849-1861.

[73] Ojeda T et al. (2011) Degradability of linear polyolefins under natural weathering. Polymer degradation and stabilility. 96: 703-707.

[74] Scott G (2002) Degradation and stabilization of carbon-chain polymers. In: Scott G, editor. Degradable polymers - principles and applications. Dordrecht/Boston/London: Kluwer Academic Publishers. pp. 27-50.

[75] Schwarzenbach $\mathrm{K}$ et al. (2009) Antioxidants. In: Zweifel H, Maier RD, Schiller M, editors. Plastics Additives Handbook. Cincinnati: Hanser. pp.1-137.

[76] Ojeda $\mathrm{T}$ et al. (2009) Abiotic and biotic degradation of oxo-biodegradable foamed polystyrene. Polymer degradation and stability. 94: 2128-2133.

[77] Chiellini E, Corti A, Swift G (2003) Biodegradation of thermally-oxidized, fragmented low-density polyethylenes. Polymer degradation and stability 81: 341-351. 